\title{
Investigation of potential distribution on a CFRP coupon under impulse current. Test results and FDTD simulation.
}

\author{
D. Romero, J.A. Rey, J. Montanya, R. Horta \\ Department of Electrical Engineering \\ Universitat Politècnica de Catalunya \\ Terrassa (Barcelona), Spain \\ romero@ee.upc.edu
}

\author{
G. Tobella \\ LABELEC high voltage laboratory \\ Terrassa (Barcelona), Spain
}

\begin{abstract}
CFRP is becoming in an important material for the future blades due to alternative renewable energy industry plans to increase the length of the blades. This work shows some analytical results about potential distribution on a CFRP coupon obtained after applying an impulse current with different rise time. Effects around electrodes are, symmetry behavior and some interesting comments about the influence of the rise time appear. A FDTD simulation is done and a comparison between FDTD and analytical results. The aim is to evaluate how useful can be this technique when current distribution is over an anisotropic material since tests are not always possible.
\end{abstract}

Keywords- lightning; wind turbines; blades; CFRP; FDTD; modelling

\section{INTRODUCTION}

Nowadays, the challenge of reducing the cost of alternative renewable energy [1] give rise to an optimization of the wind turbine performance. The best way to increase the wind energy production is to increase the swept area of the rotor by increasing the blade length. Modern wind turbines can reach altitudes of about to $200 \mathrm{~m}$ even higher in the near future [2]. Then blades length can exceed $80 \mathrm{~m}$ especially in offshore wind farm. In this scenario carbon fiber reinforced plastic (CFRP) becomes more relevant in blade manufacturing.

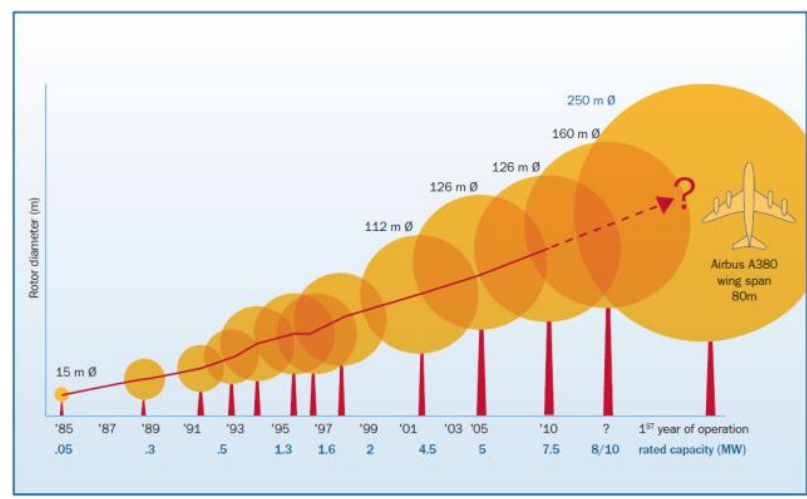

Figure 1. Evolution of wind turbines (adopted from [2]).
On the other hand, lightning protection system (LPS) in wind turbines is a very complex task and blades require a special attention because they constitute the most lightningsensitive part of a wind turbine. Materials to build the blade, size of them and their rotating speed get complicated their lightning protection [3-4]. Lightning protection of wind turbines is covered by the IEC 61400-24 standard [5], although the continuous changings in wind turbines manufacturing force a constant review of it.

In this way, impulse current tests [6] are required to verify current distribution through the different conductive part of blades (down conductors, connection components and CFRP) and how it can affect to the damage mechanisms in blades. Electrical connections between LPS and CFRP elements require an especial attention taking into account the difficulty to do it. In this context, it is becoming more important a deep knowledge about electrical behavior of CFRP. In the last years some, works about this topic has been presented [6-10] but mostly under direct current and sometimes looking for damage identification [11-13].

Due to the complexity of real test over full size blades, increasingly is more necessary simulation tools to obtain accurate results of our designs. The finite different time domain (FDTD) method is an accurate way of resolving Maxwell's equations since Yee presented it in 1966 [14]. This kind of method is able to work at high frequency and take into account all the electromagnetic properties of the materials involved in a concrete performance, becoming a perfect tool to analyze the transient magnetic fields and voltages induced over a wind turbine [15-16] or in the body of an aircraft stroked by a lightning [17]. Among all the methods to solve Maxwell's equations, FDTD is the technique that continues growing due to the availability of numerical codes and increased computer capabilities. 
This paper presents some tests under impulse current with different waveform. Taking as a reference the results obtained in a previous current distribution research [6], which it was observed that the current through CFRP had faster rise time than the current through down conductor of the LPS. For this reason, it is essential to analyze the behavior of the CFRP material under different waveform, in order to observe how the current was distributed. Some FDTD simulation are shown, trying to improve model tools because they can help the research with this composite anisotropic materials.

\section{POTENTIAL MEASUREMENT ON THE COUPON}

\section{A. Test performance}

For this work, a CFRP unidirectional ply sample is used with identical electrical characteristics to the sample tested in [7]. The configuration of the CFRP coupon and the electrodes are shown in the next figure:

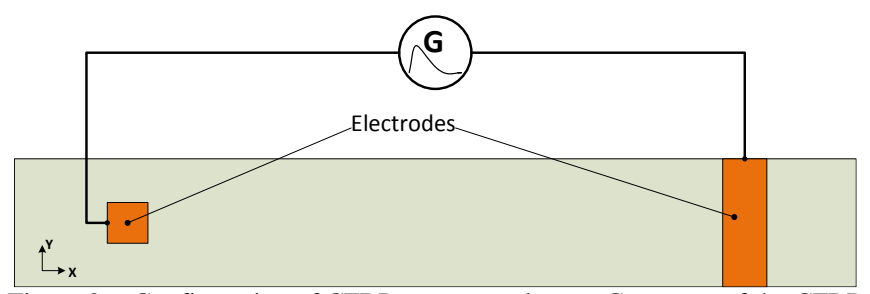

Figure 2. Configuration of CFRP coupon under test Geometry of the CFRP coupon and the electrodes. This view corresponds to the electrodes side. Xaxis correspond to the carbon fibers direction.

The CFRP coupon is $725 \mathrm{~mm}$ length, $110 \mathrm{~mm}$ width and $2.62 \mathrm{~mm}$ thickness. The electrodes location are not just in the corners of the CFRP coupon, like real full size blades.

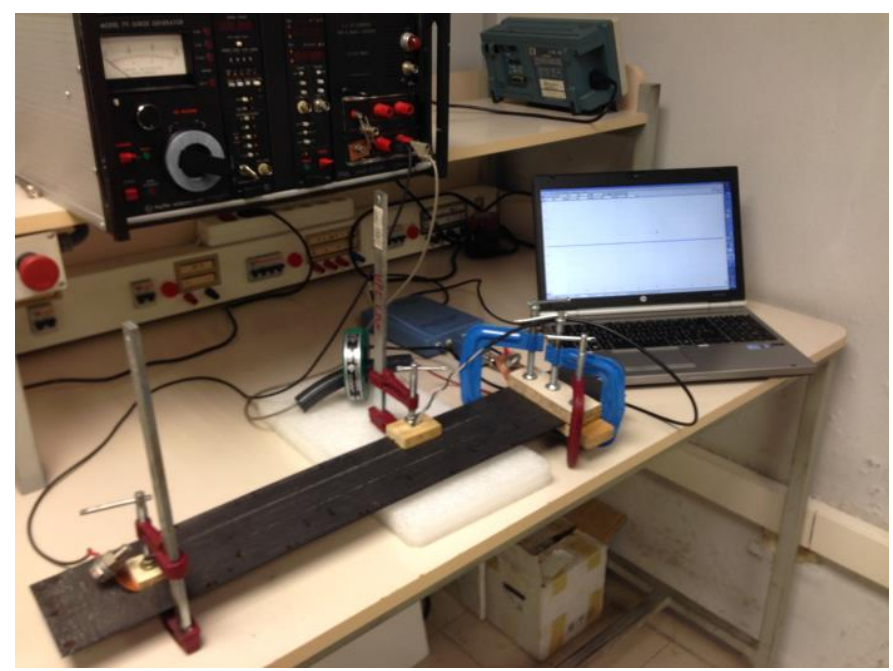

Figure 3. Test Performance. CFRP coupon connected to an impulse generator with the measurement system (digital recorder, current monitor and voltage probe).

In the same way, full size blades have not uniform width of CFRP along it. Trying to reproduce this situation, electrodes with different size is used with the idea of observing the behavior around the electrodes. The reference electrode covered the full coupon width $(110 \mathrm{~mm})$, while the injection electrode was $35 \mathrm{~mm}$ square and it is connected at the half of the width of the coupon. The free distance between electrodes is $495 \mathrm{~mm}$. C-clamps is used to fix the electrodes meanwhile an impulse current is applied. Over this sample, some different rise times were applied trying to observe potential distributions over the CFRP. Peak current was almost constant for each rise time waveform.

Potential measurement over CFRP coupon surface is not a trivial task due to the stray inductance effect of the measurement circuit especially when an impulse current is injected. For measuring the current through the coupon, it was used a Pearson 110A current monitor (CM). In the case of the voltage measured, it was performed a probe with two small electrodes with a $30 \mathrm{~mm}$ separation distance and the leads with a minimum distance over the surface, minimizing the stray inductance effect. A USB digital recorder (DR) was used to record the current and voltage signals. PicoScope 4424 digital recorder was used. It has 12 bits and a bandwidth of 20 $\mathrm{MHz}$.

\section{B. Experiment procedure}

Taking as a reference the line along the half of the width of the coupon (line A), two more line were selected on both sides of line A and they were separated from it $30 \mathrm{~mm}$ (the distance between voltage probe electrodes). Line $\mathrm{B}$ and $\mathrm{C}$ were out of the influence of the injection electrode. Along these lines some points were selected to measure voltage. Voltage names were $\boldsymbol{V}_{\boldsymbol{A} \boldsymbol{B} \boldsymbol{X}}$ ( ${ }_{\boldsymbol{A} \boldsymbol{B}}$ indicates the lines between the voltage was measured and $x$ indicates the number of the point measured).

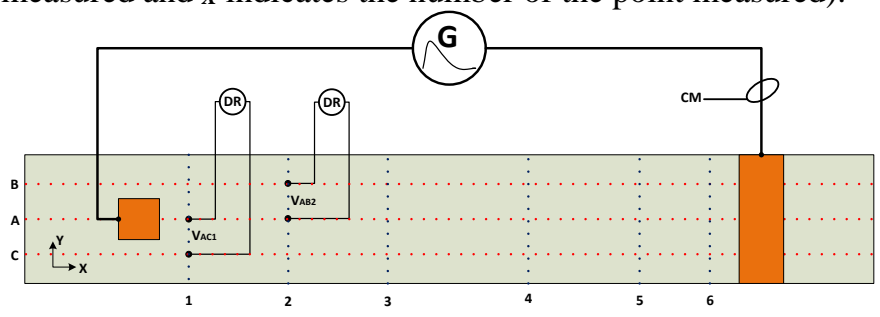

Figure 4. Measure of $\boldsymbol{V}_{\boldsymbol{A} \boldsymbol{B} \boldsymbol{X}}$ and $\boldsymbol{V}_{\boldsymbol{A} \boldsymbol{C} \boldsymbol{X}}$ voltages. Red lines shows the lines between the voltage were measured and blue lines represents the point of the measurement. Impulse current injected to the CFRP coupon in simultaneously measured with the digital recorder (DR).

In addition to $\mathrm{V}_{\mathrm{ABX}}$ and $\mathrm{V}_{\mathrm{ACX}}$ voltage measures, some voltages along line A were measured too. These voltages were called $V_{A A X}$ ( $A A$ indicates that the voltage was measured over line $\mathrm{A}$ and $x$ indicates the number of the point measured)

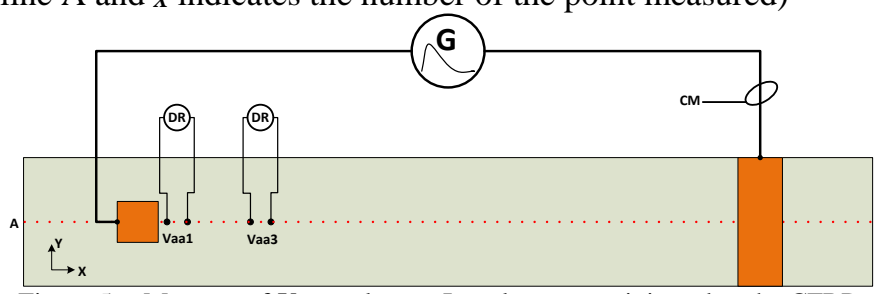

Figure 5. Measure of $\boldsymbol{V}_{\boldsymbol{A} A \boldsymbol{X}}$ voltages. Impulse current injected to the CFRP coupon in simultaneously measured with the digital recorder (DR). 
The aim of this measurement were to observe the symmetry in CFRP behavior. The connection between CFRP and the impulse current generator was not realized in the middle of the material, as it is in a real full blade connection between the down conductor of the LPS and the CFRP connection. In the same way, in DC test was observed that almost all current applied to the injection electrode was conducted through fibers in front of this electrode and fibers out of this area were not effective for the current conduction. This phenomena was clearly observed with thermal images. The idea was to determine if, with impulse current, the behavior of the CFRP were the same or not.

\section{Slow rise time impulse current}

In this case, an impulse current with around $13 \mu$ s rise time was applied. The peak value of the injected current was $280 \mathrm{~A}$ and it was almost constant during measurements. Voltage and injected current were simultaneously measured at points indicated before.

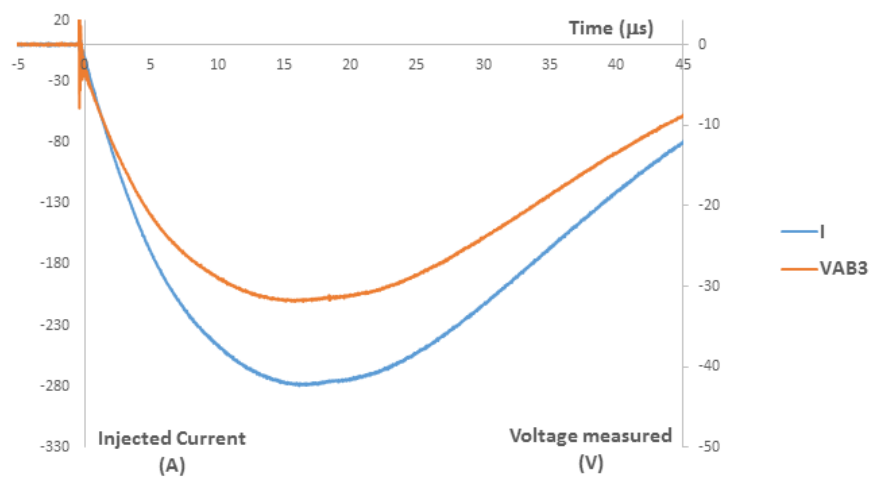

Figure 6. Example of injected current and voltage measured $\left(\boldsymbol{V}_{\boldsymbol{A B B}}\right)$.

Next table shows the impulse resistance in all points measured. It was calculated dividing peak voltage by current.

TABLE I. IMPUSLSE RESISTANCE FOR ALL $A_{\boldsymbol{B}}$ AND $_{A C}$ POINTS MEASURED

\begin{tabular}{|c|c|c|}
\hline Position (mm) & Voltage name & $\mathbf{Z}_{\mathbf{P}}(\Omega)$ \\
\hline$x=140$ & $V_{A B I}$ & 0.200 \\
\hline$x=140$ & $V_{A C 1}$ & 0.207 \\
\hline$x=225$ & $V_{A B 2}$ & 0.159 \\
\hline$x=225$ & $V_{A C 2}$ & 0.148 \\
\hline$x=310$ & $V_{A B 3}$ & 0.114 \\
\hline$x=310$ & $V_{A C 3}$ & 0.113 \\
\hline$x=430$ & $V_{A B 4}$ & 0.101 \\
\hline$x=430$ & $V_{A C 4}$ & 0.086 \\
\hline$x=525$ & $V_{A B 5}$ & 0.064 \\
\hline$x=525$ & $V_{A C 5}$ & 0.057 \\
\hline$x=585$ & $V_{A B 6}$ & 0.030 \\
\hline$x=585$ & $V_{A C 6}$ & 0.031 \\
\hline
\end{tabular}

TABLE II. IMPUSLSE RESISTANCE FOR ALL ${ }_{A A}$ POINTS MEASURED

\begin{tabular}{|c|c|c|}
\hline Position $(\mathbf{m m})^{\mathbf{a}}$ & Voltage name & $\mathbf{Z}_{\mathbf{P}}(\boldsymbol{\Omega})$ \\
\hline $\mathrm{x}=125$ & $\boldsymbol{V}_{\boldsymbol{A A \boldsymbol { }}}$ & 0.018 \\
\hline $\mathrm{x}=200$ & $\boldsymbol{V}_{\boldsymbol{A A} \mathbf{2}}$ & 0.010 \\
\hline $\mathrm{x}=230$ & $\boldsymbol{V}_{\boldsymbol{A A 3}}$ & 0.009 \\
\hline $\mathrm{x}=330$ & $\boldsymbol{V}_{\boldsymbol{A A 4}}$ & 0.009 \\
\hline $\mathrm{x}=425$ & $\boldsymbol{V}_{\boldsymbol{A A 5}}$ & 0.010 \\
\hline $\mathrm{x}=505$ & $\boldsymbol{V}_{\boldsymbol{A A \boldsymbol { }}}$ & 0.012 \\
\hline $\mathrm{x}=575$ & $\boldsymbol{V}_{\boldsymbol{A A} 7}$ & 0.017 \\
\hline
\end{tabular}

a. Position indicates the coordinates of the positive probe electrode. The negative probe electrode was $30 \mathrm{~mm}$ separated in the same line.

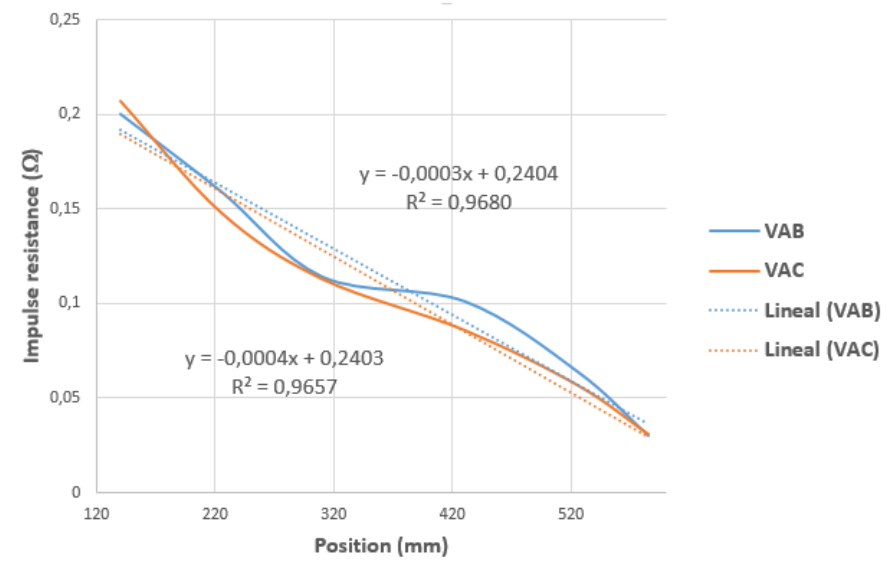

Figure 7. Potential $V_{A B X}$ and $V_{A C X}$ along the CFRP coupon with a slow rise time impulse current.

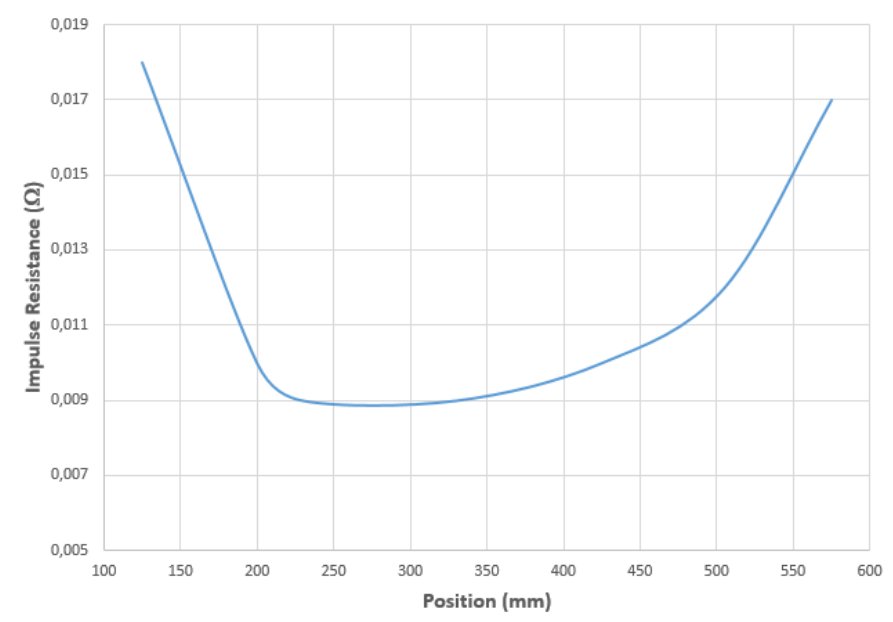

Figure 8. Potential $V_{A A X}$ along the CFRP coupon with a slow rise time impulse current.

\section{Fast rise time impulse current}

In this case, an impulse current with around $3 \mu$ s rise time was applied. The peak value of the injected current was $460 \mathrm{~A}$ and it was almost constant during measurements. Voltage and injected current were simultaneously measured at points indicated before. 


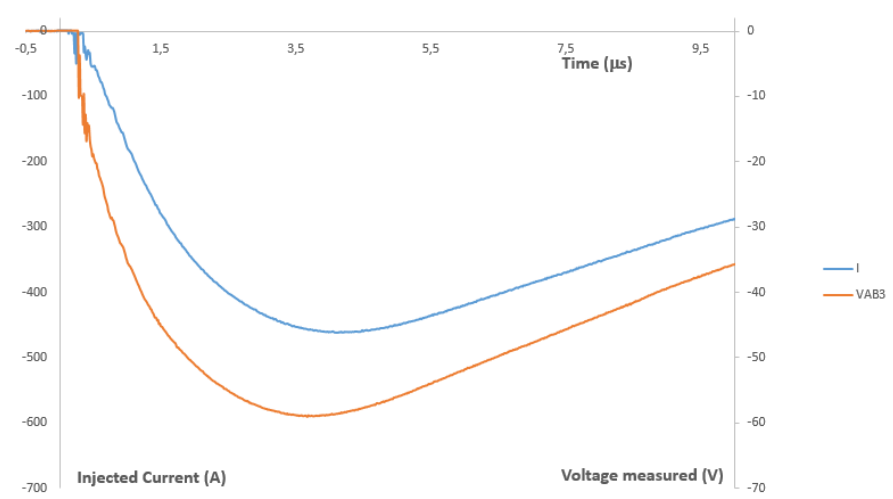

Figure 9. Example of injected current and voltage measured $\left(\boldsymbol{V}_{\boldsymbol{A} B 3}\right)$.

Next table shows the impulse resistance in all points measured. It was calculated dividing peak voltage by peak current. Figure 7 shows a delay between voltage and current that it didn't appear with slow rise time. It was not taken into account for the impulse resistance.

In the following table, it can be observed the impulse resistance in all points measured. It was calculated dividing peak voltage by peak current.

TABLE III. IMPUSLSE RESISTANCE FOR ALL ${ }_{\boldsymbol{A}} \boldsymbol{B}$ AND $A \boldsymbol{A}$ POINTS MEASURED

\begin{tabular}{|c|c|c|}
\hline Position (mm) & Voltage name & $\mathbf{Z}_{\mathbf{P}}(\Omega)$ \\
\hline$x=140$ & $V_{A B 1}$ & 0.190 \\
\hline$x=140$ & $V_{A C I}$ & 0.207 \\
\hline$x=225$ & $V_{A B 2}$ & 0.160 \\
\hline$x=225$ & $V_{A C 2}$ & 0.162 \\
\hline$x=310$ & $V_{A B 3}$ & 0.128 \\
\hline$x=310$ & $V_{A C 3}$ & 0.133 \\
\hline$x=430$ & $V_{A B 4}$ & 0.094 \\
\hline$x=430$ & $V_{A C 4}$ & 0.094 \\
\hline$x=525$ & $V_{A B 5}$ & 0.056 \\
\hline$x=525$ & $V_{A C 5}$ & 0.052 \\
\hline$x=585$ & $V_{A B 6}$ & 0.028 \\
\hline$x=585$ & $V_{A C 6}$ & 0.036 \\
\hline
\end{tabular}

TABLE IV. IMPUSLSE RESISTANCE FOR ALL ${ }_{A A}$ POINTS MEASURED

\begin{tabular}{|c|c|c|}
\hline Position (mm) & Voltage name & $\mathbf{Z}_{\mathbf{P}}(\boldsymbol{\Omega})$ \\
\hline $\mathrm{x}=125$ & $\boldsymbol{V}_{\boldsymbol{A A 1}}$ & 0.234 \\
\hline $\mathrm{x}=200$ & $\boldsymbol{V}_{\boldsymbol{A A 2}}$ & 0.116 \\
\hline $\mathrm{x}=230$ & $\boldsymbol{V}_{\boldsymbol{A A 3}}$ & 0.100 \\
\hline $\mathrm{x}=330$ & $\boldsymbol{V}_{\boldsymbol{A A 4}}$ & 0.101 \\
\hline $\mathrm{x}=425$ & $\boldsymbol{V}_{\boldsymbol{A A 5}}$ & 0.098 \\
\hline $\mathrm{x}=505$ & $\boldsymbol{V}_{\boldsymbol{A A 6}}$ & 0.129 \\
\hline $\mathrm{x}=575$ & $\boldsymbol{V}_{\boldsymbol{A A} 7}$ & 0.145 \\
\hline
\end{tabular}

a. Position indicates the coordinates of the positive probe electrode. The negative probe electrode was $30 \mathrm{~mm}$ separated in the same line.

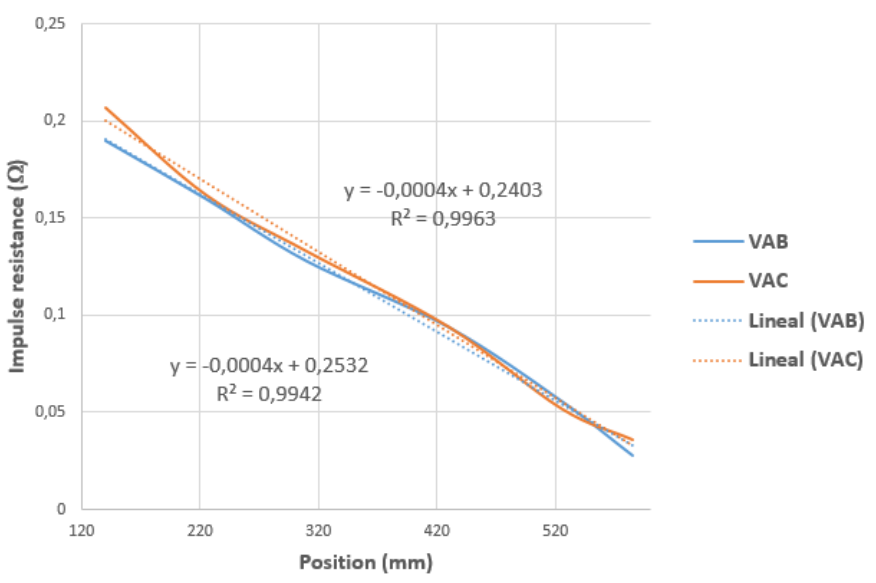

Figure 10. Potential $\boldsymbol{V}_{\boldsymbol{A} \boldsymbol{B} \boldsymbol{X}}$ and $\boldsymbol{V}_{\boldsymbol{A} C \boldsymbol{X}}$ along the CFRP coupon with a fast rise time impulse current.

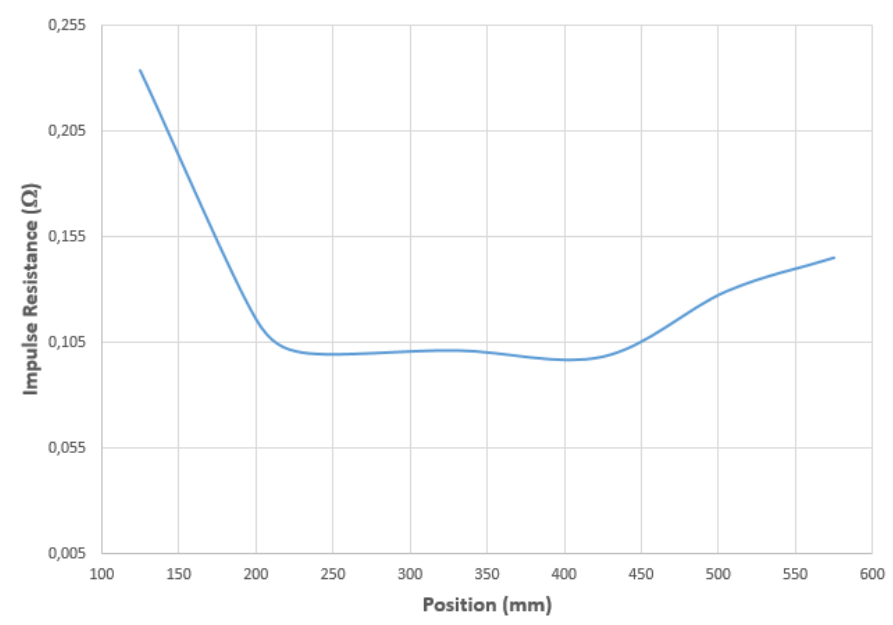

Figure 11. Potential $\boldsymbol{V}_{\boldsymbol{A} \boldsymbol{A} \boldsymbol{X}}$ along the CFRP coupon with a fast rise time impulse current.

\section{E. Discussion about results}

After the results analysis, some interesting things could be observed. First of all, results show symmetric behavior, impulse resistance in both sides are very similar. Furthermore, impulse resistance in these points along CFRP coupon are almost equal, whereas with slower rise time is not as linear as faster rise time.

On the other hand, around the electrodes, potential concentration is more intensive than in the middle of the CFRP. Similar results were obtained with DC [7], although in this occasion, when the results from the different rise time were compared, a different behavior was observed. With a faster rise time, the potential concentration near reference electrode seems lower than slower rise time. Near injection electrode similar behavior appears. This trend should be analyzed specifically with more measurements around the electrodes.

Results show similar values for impulse resistance between $\mathrm{AB}$ lines and $\mathrm{AC}$ lines for all points and for both waveforms. For impulse resistance over line A (where greater part of the 
injected current go through), the values are very different if the data from the two waveforms are compared. It indicates different effective conduction area depending of the rise time or the current density.

Another important result is the observation of the delay between the potential and the current injected for faster rise time while for slower rise time resistive behavior prevail. This delay should be more investigated even the stray inductance effect of the measurement system was minimize.

The anisotropic behavior of CFRP and the irregularities in the fabrication of the coupon could justify these results but more test should be done. Contact resistance has not been taken into account in this work.

\section{FDTD SIMULATIONS}

\section{A. Simulation performance}

Different parameters have been taken into consideration to carry on the FDTD modelling. First of all, the following values have introduced for the scale of the analytical space: $0.18 \mathrm{~m} \times 0.074 \mathrm{~m} \times 0.01 \mathrm{~m}$. This space was divided into $1 \mathrm{e}-3$ cubic cells.

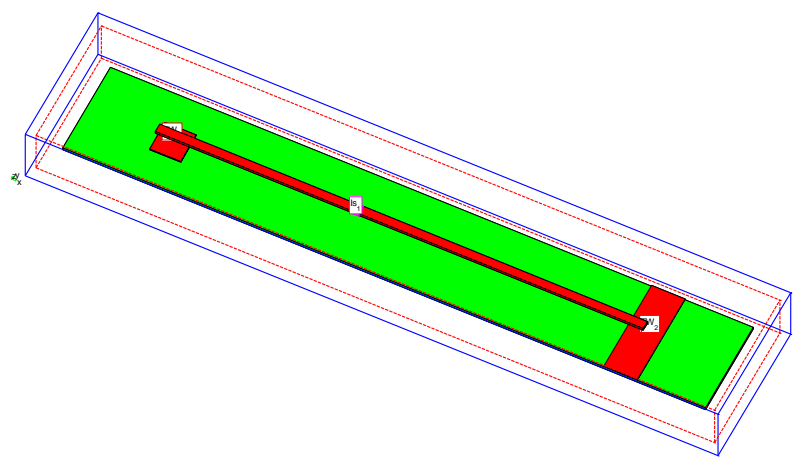

Figure 12. Geometry of the model

Secondly, to achieve the $2 \mu$ s rise time with the dimension of the unit cells determined before, it was required a number of time steps of 384000 .

Finally, this simulation required a CPML (Convolutional Perfectly Matched Layer) boundaries, because the standard ones were shown to be ineffective for absorbing evanescence waves [18]. For this reason, this other kind of boundaries were implemented according to the following settings: air buffer boundary with 20 cells in each side of the model and 8 cells of CPML boundaries.

\section{B. Results and discussion}

First of all, result of current density distribution from the FDTD simulation is showed. It shows how the current spreads from the injection current to the reference current. Potential distribution around the electrodes could be analyzed from these simulations but they need real test to validate the results.

Current density

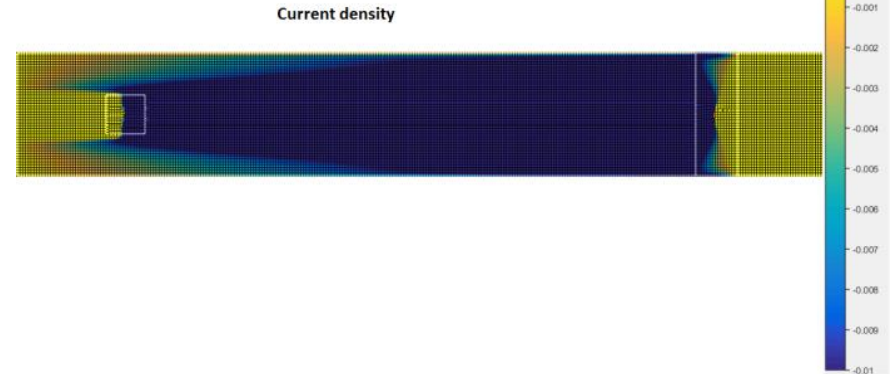

Figure 13. Current density on CFRP coupon obtained from FDTD simulation.

Similar data was obtained from FDTD simulation to compare them with data obtain from the tests. Injected impulse current and potential could be calculated.

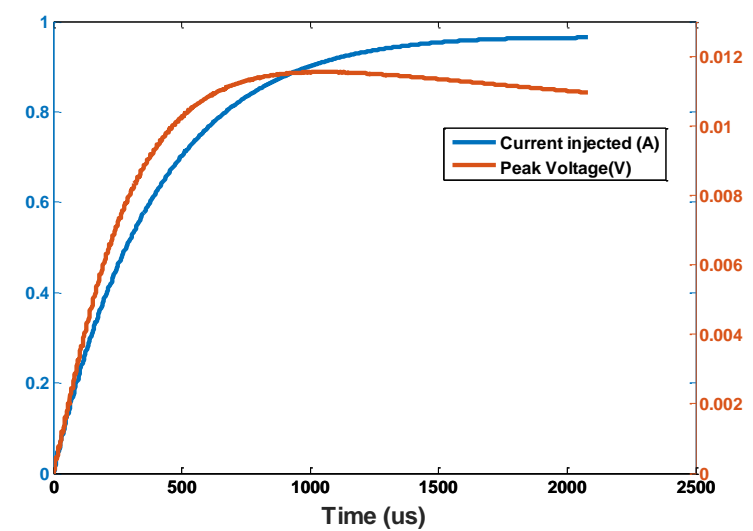

Figure 14. Example of injected current and voltage measurement from FDTD simulation.

Figure 14 shows a delay between voltage and injected current like measurement obtained from faster rise time and it may indicated that this delay is not introduced from the measurement system.

TABLE V. IMPUSLSE RESISTANCE FOR ALL $\boldsymbol{A} \boldsymbol{B}$ POINTS MEASURED

\begin{tabular}{|c|c|c|}
\hline Position (mm) & Voltage name & $\mathbf{Z}_{\mathbf{P}}(\boldsymbol{\Omega})$ \\
\hline $\mathrm{x}=140$ & $\boldsymbol{V}_{\boldsymbol{A B 1}}$ & 0.037 \\
\hline $\mathrm{x}=225$ & $\boldsymbol{V}_{\boldsymbol{A B} \mathbf{2}}$ & 0.025 \\
\hline $\mathrm{x}=310$ & $\boldsymbol{V}_{\boldsymbol{A B 3}}$ & 0.018 \\
\hline $\mathrm{x}=525$ & $\boldsymbol{V}_{\boldsymbol{A B} 5}$ & 0,005 \\
\hline
\end{tabular}

TABLE VI. IMPUSLSE RESISTANCE FOR ALL ${ }_{\boldsymbol{A} A}$ POINTS MEASURED

\begin{tabular}{|c|c|c|}
\hline Position (mm) & Voltage name & $\mathbf{Z}_{\mathbf{P}}(\mathbf{m} \boldsymbol{\Omega})$ \\
\hline $\mathrm{x}=125$ & $\boldsymbol{V}_{\boldsymbol{A A I}}$ & 5.85 \\
\hline $\mathrm{x}=225$ & $\boldsymbol{V}_{\boldsymbol{A A \boldsymbol { }}}$ & 4.94 \\
\hline $\mathrm{x}=430$ & $\boldsymbol{V}_{\boldsymbol{A A 3}}$ & 4.09 \\
\hline $\mathrm{x}=525$ & $\boldsymbol{V}_{\boldsymbol{A A 4}}$ & 4.14 \\
\hline \multicolumn{2}{|c|}{ a. Position indicates the coordinates of the positive probe electrode. The }
\end{tabular}
negative probe electrode was $30 \mathrm{~mm}$ separated in the same line. 
$\boldsymbol{V}_{A C X}$ voltages are not showed on TABLE V because are the same than $\boldsymbol{V}_{\boldsymbol{A} \boldsymbol{B} X}$ voltages due to the symmetry of the model.

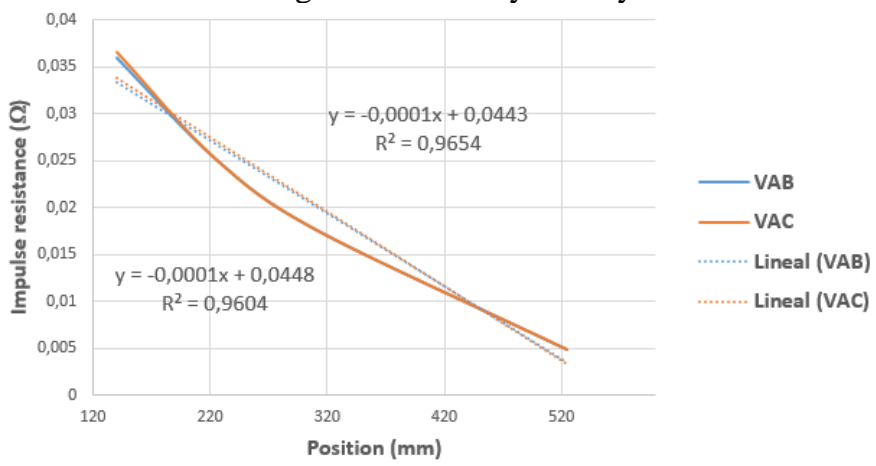

Figure 15. Potential $\boldsymbol{V}_{\boldsymbol{A} \boldsymbol{B} X}$ and $\boldsymbol{V}_{\boldsymbol{A} C X}$ along the CFRP coupon obtained from FDTD simulation.

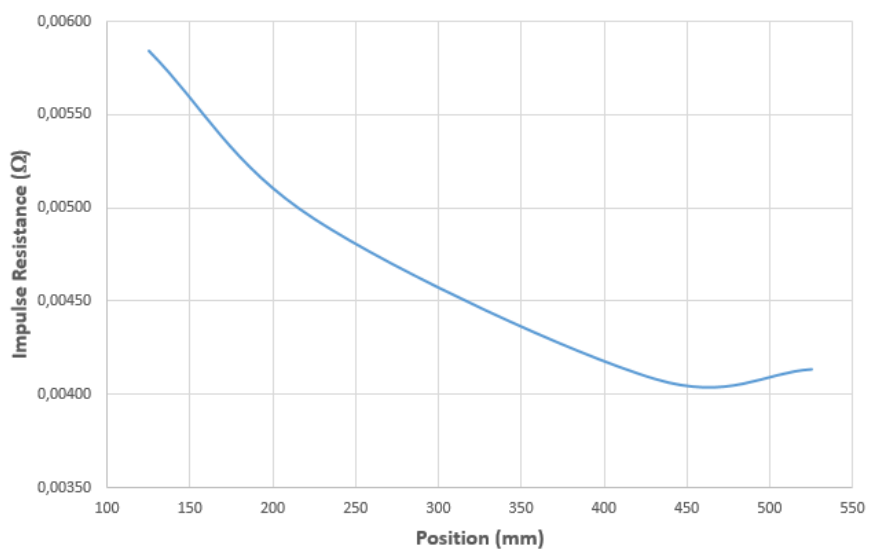

Figure 16. Potential $\boldsymbol{V}_{\boldsymbol{A} \boldsymbol{A} X}$ along the CFRP coupon with a fast rise time impulse current.

Although in this case, potential concentration around electrodes are not as evidence than analytical results some similarities can be observed. More points should be calculated to improve the graphic.

\section{CONCLUSIONS}

In this paper, it was obtained the surface potentials for impulse current with different rise time in a CFRP coupon. Symmetry behavior in the fibers direction and near the electrodes were analyzed. Different behaviors around electrodes were observed when the rise time of the impulse current increased. In addition to this, a delay between voltage and current injected was observed when the rise time of the impulse current increased. This delay appear in the FDTD simulation too. FDTD could be an important tool to help the research work in this area. All the results presented could be useful for lightning protection of CFRP in wind turbine but some more test and measurements should be done to delve into in the CFRP behavior knowledge.

\section{ACKNOWLEDGMENT}

This study was supported by research grants from the Spanish Ministry of Economy and Competitiveness
(MINECO) AYA2011-29936-C05-04, ESP2013-48032-C5-3$\mathrm{R}$, and Centre for the Development of Industrial Technology (CDTI) EEA GRANTS project IDI-20140071. The authors wish to thank LABELEC high voltage laboratory to allow test execution.

\section{REFERENCES}

[1] J. Korsgaard, "Flexible blade length concept reduces cost of offshore wind energy by up to 10 percent", EWEA Offshore 2015, Copenhagen, Denmark.

[2] EWEA - UpWind, "Design limits and solutions for very large wind turbines", 2011.

[3] F. Rachidi, M. Rubinstein, J. Montanyà, J. L. Bermudez, R. Rodriguez, G. Solà, and N. Korovkin, "Review of current issues in lightning protection of new generation wind turbine blades," IEEE Trans. Ind. Electron., vol. 55(6), pp. 2489-2496, 2008.

[4] S. Yokoyama et al., "Lightning Protection of Wind Turbine Blades", Electra, pp. 42-45, June 2014.

[5] "IEC 61400-24 - Wind turbine generator systems - Part 24: Lightning protection", International Electrotechnical Commission, Edition $1.0-$ 2010-06.

[6] D. Romero, J. Montanyà and J. Vink, "Test and simulation of lightning current distribution on a wind turbine blade," in Proc. of the 32 nd Intl. Conf. on Lightning Protection (ICLP), Shanghai, China, 2014.

[7] J. Montanyà, D. Romero, R. López and G. Tobella, "Experimental determination of potential distribution on a CFRP laminate and thermal images of DC and impulse currents: evaluation of connections", AsiaPacific International Conference on Lightning (APL), Nagoya, Japan, 2015.

[8] A. Piche, I. Revel, and G. Peres, "Experimental and Numerical Methods to Characterize Electrical Behaviour of Carbon Fiber Composites Used in Aeronautic Industry," Advances in Composite Materials - Analysis of Natural and Man-Made Materials, Dr. Pavla Tesinova (Ed.), InTech, 2011.

[9] R. Abid, A. Haddad, H. Griffiths. D. Clark, M. Coleans and S. Evans, "Electrical Characterization of Aerospace Graded Carbon Fiber Reinforced Plastic Composites Under Low Current DC and Impulse Energizations," in Proc. of the Intl. Conf. on Lightning and Static Electricity, Seattle, SU, September 2013.

[10] T. Nishi, H. Tsubata, and H. Fujita, "Lightning Current Flow Analysis and Measurement of the Composite Structure," in Proc. of the Intl. Conf. on Lightning and Static Electricity, Seattle, SU, September 2013.

[11] R. Schueler, S. P. Joshi, and K. Schulte, "Damage detection in CFRP by electrical conductivity mapping," Composites Science and Technology, Vol. 61, pp. 921-930, 2001.

[12] A. Baltopoulos, N. Polydorides, L. Pambaguian, A. Vavouliotis, and V. Kostopoulos, "Damage identification in carbon fiber reinforced polymer plates using electrical resistance tomography mapping," Journal of Composite Materials, DOI: 10.1177/0021998312464079.

[13] A. Todoroki, " Long Life Durability of Electrodes of Electrical Resistance Change Method for Damage Monitoring of CFRP Composite Structures," Tokyo Inst of Tech (Japan) Final Report 2008 AOARD-074039 (http://www.dtic.mil/dtic/tr/fulltext/u2/a481816.pdf).

[14] K. S. Yee, "Numerical solution of initial boundary value problems involving maxwell equations in isotropic media," IEEE Trans. Antennas. Propagat., vol. AP-14, pp. 302-307, May 1966.

[15] [2] Sakata, T.,K. Yamamoto, S. Sekioka and S. Yokoyama, "Risk evaluation of lightning damage to wind turbines with the electrogeometrical method", International Workshop on High Voltage Engineering, EO-07-46, SP-07-22, HV-07-46, pp. 43-48, 2007.

[16] Yamamoto, K., T. Noda, S. Yokoyama and A. Ametani, "An experimental study of lightning overvoltages in wind turbine generation systems using a reduced-size model", Electrical Engineering in Japan, vol. 158 , no. 4 , pp. $2230,2007-3$. 
[17] M. S. Sarto, "A new model for the FDTD analysis of the shielding performances of thin composite structures," IEEE Trans. Electromagn. Compat.,vol. 41, no. 4, pp. 298-306, Nov. 1999.

[18] J.Roden and S.Gedney, " Convolution PML (CPML): an efficient FDTD implementation of the CFS-PML for arbitrary media, "Microwave and Optical Technology Letters,vol27, no.5,pp.334-339,2000. 